\title{
POLÍTICAS DE QUALIFICAÇÃO DA EDUCAÇÃO: A META 07 DO PLANO ESTADUAL DE EDUCAÇÃO DE MS EM QUESTÃO
}

\author{
POLÍTICAS DE CALIFICACIÓN DE LA EDUCACIÓN: LA META 07 DEL \\ PLAN ESTADUAL DE EDUCACIÓN DE MS EN CUESTIÓN
}

QUALIFICATION POLICIES FOR EDUCATION: THE NUMBER 07 OF THE MATO GROSSO DO SUL'S STATE PLAN OF EDUCATION IN QUESTION

Milene Dias AMORIM ${ }^{1}$

RESUMO: Objetiva-se aqui analisar a concepção de qualidade presente no Plano Estadual de Educação do estado de Mato Grosso do Sul de 2014, mais precisamente sua meta 07, que tem como tema central a "qualidade da educação". Para tanto, serão utilizadas a análise bibliográfica da literatura concernente ao assunto e a análise documental, que terá como principal fonte de estudo o PEEMS/2014. Também foram utilizados dados estatísticos para melhor contextualizar o cenário educacional estadual. Conclui-se que o plano estadual de MS faz menção a uma qualidade socialmente referenciada, porém suas estratégias se engendram por perspectivas gerencialistas na medida em que dá grande ênfase às avaliações em larga escala, chegando a tratá-las como fundamental para a garantia de uma educação com qualidade.

PALAVRAS-CHAVES: Política educacional. Qualidade da educação. Plano de educação.

RESUMEN: Se pretende aquí analizar la concepción de calidad presente en el Plan Estadual de Educación del estado de Mato Grosso do Sul de 2014, más precisamente su meta 07, que tiene como tema central la "calidad de la educación". Para ello, se utilizarán el análisis bibliográfico de la literatura concerniente al asunto y el análisis documental, que tendrá como principal fuente de estudio el PEEMS / 2014. También se utilizaron datos estadísticos para mejor contextualizar el escenario educativo estadual. Se concluye que el plan estadual de MS hace mención a una calidad socialmente referenciada, pero sus estrategias se engendran por perspectivas gerencialistas en la medida en que da gran énfasis a las evaluaciones a gran escala, llegando a tratarlas como fundamental para la garantía de una educación con calidad.

PALABRAS CLAVES: Política educativa. Calidad de la educación. Plan de educación.

ABSTRACT: The purpose of this study is to analyze the quality concept present in the Mato Grosso do Sul's State Plan of Education for 2014; more precisely its aim number 07, which has as its central theme the "quality in education". In order to do so,

${ }^{1}$ Universidade Estadual de Mato Grosso do Sul (UEMS), Naviraí - MS - Brasil. Docente na UEMS. ORCID: <http://orcid.org/0000-0002-5292-1173>. E-mail: mileneamorim@gmail.com

RPGE- Revista on line de Política e Gestão Educacional, Araraquara, v. 22, n. 2, p. 482-497, maio/ago., 2018. ISSN: 1519-9029. DOI: 10.22633/rpge.v22.n2.maio/ago.2018.11168 
bibliographic analysis of the literature concerning the subject and documentary analysis, which has as main source of study the PEEMS/2014, is used. Statistical data were also used to better contextualize the state's educational scenario. As a conclusion, the MS' state plan refers to a socially referenced quality, however, its strategies are generated by managerial perspectives, once a strong emphasis is given to large-scale evaluations, treating them as fundamental for guaranteeing an education of quality.

KEYWORDS: Educational policy. Quality in education. Education plan.

\section{Introdução}

A qualidade da educação vem sendo assunto de debates constantes ao longo das últimas três décadas no cenário nacional e internacional. Nesse sentido, objetiva-se aqui analisar a concepção de qualidade presente no Plano Estadual de Educação do estado de Mato Grosso do Sul de 2014, que será tratado de agora em diante como PEEMS/2014; mais precisamente de sua meta 07 que tem como tema central a "qualidade da educação".

Pretende-se, a partir da análise do plano estadual, que já tem na sua existência uma determinação atendida do Plano Nacional de Educação, visualizar quais são os fatores e medidas que os atores locais têm considerado para ofertar qualidade a sua educação. Para tanto, será utilizada a análise bibliográfica da literatura concernente ao assunto qualidade da educação como base teórica; com destaque para Oliveira (2007), Fonseca (2009), Oliveira e Araújo (2005) e Paro (1998), e análise de conteúdo documental que terá como principal fonte de estudo o PEEMS/2014. Também foram utilizados dados estatísticos do censo escolar de MS e do Instituto Brasileiro de Geografia e Estatística (IBGE) para melhor contextualizar o cenário educacional estadual.

Tem-se aqui uma relação de grande força e complexidade entre qualidade e planejamento, uma vez que ambos dão abertura para serem tratados e moldados de acordo com interesses, e, uma vez que se defende aqui uma qualidade e um planejamento socialmente referenciados, cabe aos atores locais, executores das políticas públicas nacionais, atribuírem cidadania e equidade, enfim, humanização, a essa relação.

\section{A qualidade da educação como conceito histórico e dinâmico}


Falar sobre qualidade da educação é falar de algo questionável, complexo e de concepções diversas, variando de contexto, interesse e ideais; se diferenciando também em cada época. Ao longo dos anos, portanto, o seu conceito foi assumindo novas características de acordo com as necessidades da sociedade vigente. Deve-se considerar também que os termos quantidade e qualidade, no que diz respeito à educação básica, por diversas vezes são abordados de modo antagônicos, uma vez que, anteriormente à preocupação com a qualidade do ensino e da aprendizagem, o acesso vem sendo tratado com preferência, pois se trata de um direito previsto em Lei (OLIVEIRA; ARAÚJO, 2005; OLIVEIRA, 2007).

Nesse sentido, mesmo o Brasil tendo conquistado avanços importantes para a educação ao longo dos anos, a qualidade segue problematizada no tocante à proficiência, permanência, progressão, conclusão, duração e, pode-se dizer até mesmo no acesso (FREITAS, 2008). Uma vez que este último, ainda deixa um número considerável de brasileiros fora das instituições de ensino, mais precisamente são 3.846.109 pessoas de 04 a 17 anos de idade sem acesso ao principal direito que os tornam efetivamente cidadãos, segundo micro dados do Censo de 2010 do IBGE.

O problema da qualidade sempre esteve presente no âmbito educacional do ensino e da aprendizagem, mas nunca havia alcançado antes esse grau de centralidade, vindo, ao longo do tempo, a substituir a problemática da igualdade de oportunidades, que no passado era o alvo das discussões (ENGUITA, 1996). Atualmente, debater a qualidade da/na ou para a educação remete-se a esclarecer qual educação está sendo almejada para os sujeitos sociais, pois essa é uma questão que reflete várias concepções acerca de mundo, de homem e, ainda,

\begin{abstract}
Os conceitos, as concepções e as representações sobre o que vem a ser uma Educação de Qualidade [pois estas] alteram se no tempo e espaço, especialmente se considerarmos as transformações mais prementes da sociedade contemporânea, dado as novas demandas e exigências sociais, decorrentes das alterações que embasam a reestruturação produtiva em curso (DOURADO; OLIVEIRA; SANTOS, 2007, p. 7).
\end{abstract}

No Brasil, o grande desafio da busca pela qualidade se refere principalmente à heterogeneidade econômica, social e cultural do país, não sendo possível discutir um único padrão de qualidade nacional, quando, por exemplo, o que uma determinada região designa como qualidade para sua educação não será a mesma para outras regiões, ou mesmo, a qualidade necessária e almejada por uma escola de periferia não 
essencialmente será a mesma qualidade desejada por uma escola que atende alunos de uma classe abastada.

Nessa mesma direção, Paro (1998) menciona que a escola é uma das únicas instituições para cujo produto não há padrões definidos de qualidade a ser seguido, talvez isso ocorra pela extrema complexidade que envolve a construção desse conceito. Diferentemente de outros bens e serviços, cujo consumo se dá de forma mais ou menos definida, sendo permitido aferir imediatamente sua qualidade, os efeitos da educação sobre o indivíduo se estendem por toda sua vida, acarretando a extensão de sua avaliação por todo esse período.

A qualidade do ensino e do aprendizado do aluno está diretamente ligada às condições intra e extraescolares e aos diferentes atores individuais e institucionais. $\mathrm{Na}$ condição de extraescolar deve-se atentar para as influências econômicas, sociais e culturais das famílias e dos estudantes no processo ensino-aprendizagem, que podem impedir ou favorecer o sucesso de ações que oferecem maior qualidade a educação. Esses são elementos fundamentais que influenciam direta ou indiretamente na situação escolar (DOURADO; OLIVEIRA; SANTOS, 2007).

$\mathrm{Na}$ condição intraescolar tem-se a falta de formação docente e do pessoal de apoio escolar, bem como dos gestores; além de infraestruturas precárias, problemas com o grande número de alunos por sala, entre outros elementos que por vezes impedem o sucesso das atividades do professor e o processo de ensino-aprendizagem.

Por outro lado, se faz certo ressaltar que o conceito de qualidade é originário da área econômica e foi vinculado à educação, ou seja, ocorreu uma "transposição direta do conceito de qualidade própria dos negócios comerciais para o campo dos direitos sociais e, nestes, a educação pública" (SILVA, 2009, p. 219).

Do ponto de vista econômico, desde a infância somos inseridos nas práticas comerciais e fazemos opções. Não se trata de analisar como fazemos escolhas. No entanto, um dos elementos que acionamos é a qualidade da coisa a ser adquirida. É neste momento, então, que elegemos os elementos que expressam qualidade, segundo valores e visões de mundo (SILVA, 2009, p. 218).

Com o fortalecimento dos preceitos neoliberais no campo educacional, aguçados pelos organismos internacionais, o discurso da qualidade é incorporado e associado à formação para o trabalho, descaracterizando a educação enquanto direito social.

Nessa perspectiva, a qualidade não é entendida como algo que deva qualificar o direito à educação, mas sim ser atributo potencialmente adquirível no mercado dos bens 
educacionais, e, sendo assim, não poderá estar ao alcance de todos, pois ao se tornar um produto, terá um preço, e quanto maior for a qualidade, maior será o seu valor econômico e maior será o número de pessoas excluídas do seu usufruto (GENTILI, 2007).

Tratando a qualidade como produto, a tendência é impulsionar a competitividade e desresponsabilizar cada vez mais o Estado de seus deveres, pois ao alimentar o ideário de que só é de qualidade o que é pago ou privado, as famílias aumentam suas dívidas injetando dinheiro no mercado por uma educação melhor para seus filhos (FONSECA; OLIVEIRA, 2007).

A qualidade, nesse aspecto mercantil e produtivista, é definida no mundo dos negócios como algo mensurável que deve ser medido por instrumentos padrões ou unificadores. Nesse sentido, medir a qualidade significa grandes possibilidades de melhorá-la, assim como divulgar seus resultados é dar grande atenção para o produto final. Essas características, somadas aos padrões, rankings, testes comparativos, à hierarquização e estandardização próprias do âmbito mercantil, são de fácil localização no meio educacional (GENTILI, 2007; FONSECA, OLIVEIRA, 2007; SILVA, 2009).

A grande ênfase dada à qualidade do ensino tem sua origem nas grandes discussões internacionais sobre a educação e possui como impulsionadores órgãos como a ONU, a UNESCO e o Banco Mundial, que possuem grande poder de influência nos países, principalmente nos mais pobres e em desenvolvimento.

É com a alegação de que novos tempos, novas exigências e novas necessidades exigem uma nova qualidade, que as agências internacionais introduzem reformas educacionais que vão ao encontro das novas necessidades geradas pela reorganização produtiva do capitalismo. Tais reformas são direcionadas para mudanças no currículo, na gestão da educação, na avaliação dos sistemas e na formação profissional docente (LIBÂNEO, OLIVEIRA, TOSCHI, 2008).

Os mesmos autores vêm afirmar que há uma grande preocupação dos organismos internacionais em não somente traçar políticas educacionais e reformular o papel do Estado, como também em atacar a exclusão, a segregação e a marginalização social, uma vez que esses são fatores que impedem o desenvolvimento do capitalismo por ameaçar a estabilidade e a ordem dos países ricos.

Warde (1992) também menciona alguns pontos característicos desse modelo gerencial de qualidade, onde a estratégia proposta pelos organismos internacionais supõe um esforço sistêmico e reporta-se aos objetivos de cidadania e competitividade. 
Têm como critérios inspiradores as políticas de equidade e desempenho, e como direção das reformas institucionais a integração nacional, a descentralização, a lógica da eficácia e eficiência, além de transparecer uma qualidade individualista, privatizada e de mercado, até mesmo uma qualidade voltada restritamente para a formação de consumidores.

O Brasil, ao compactuar com a lógica internacional, vem se apropriando, em suas políticas, do discurso da modernização educacional, onde a diversificação, a flexibilização, a competitividade, a produtividade, a eficiência e, principalmente, a qualidade dos sistemas educativos das escolas e do ensino têm grande presença, adequando-as à ótica neoliberal, principalmente, por meio de avaliações padronizadas.

Tomando os instrumentos de avaliação como fundamentais para a qualidade da educação, tem-se uma concepção atrelada a números que podem não refletir a real condição da educação avaliada. O quantitativo é de suma importância para a qualidade, pois é propulsor desta; no entanto, a qualidade perpassa a quantidade.

Quando se olha a qualidade somente pela ótica da quantidade, corre-se o risco de promover a ampliação dos números sem que o nível de conhecimento e de formação humana seja ampliado. Demo (2006) demonstra que não bastam altas taxas de matrículas se depois o número de evasão for exorbitante; grandes números de professores, alunos e funcionários, sem cuidar do aprimoramento e desempenho qualitativo desses; a presença de prédios novos, multiplicidade de materiais e espaços bem cuidados, sem saber o que fazer com eles; da mesma forma, não adianta perseguirse altas notas em provas de larga escala, se os jovens continuam saindo do ensino médio na condição de analfabetos funcionais.

Dessa forma, defende-se aqui uma educação que ao mesmo tempo em que disponha de quantidades também se sobressaia na qualidade pretendida hoje entre os educadores, que se desenvolva a partir de uma educação que promova a ruptura internacional, superando o modelo dominante, tecnicista e mercadológico que está sendo posto, humanizando as ações governamentais e minimizando as intervenções externas que tentam inculcar um modelo mundialmente comum à educação. Nessa perspectiva, vislumbra-se uma qualidade socialmente referenciada, que faça apologia à cidadania e à democratização não só do acesso, mas também do conhecimento.

\section{A meta 07 do PEEMS/2014: apontamentos sobre a qualidade da educação no estado}


O atual Plano Estadual de Educação de Mato Grosso do Sul está firmado na Lei $\mathrm{n}^{\circ} 4.621$ de 22 de dezembro de 2014. Sua criação vem atender ao Art. $8^{\circ}$ da Lei $n^{\circ}$ 13.005/2014, que instituiu o Plano Nacional de Educação (2014-2024), o qual determina que

Os estados, o Distrito Federal e os municípios deverão elaborar seus correspondentes planos de educação, ou adequar os planos já aprovados em lei, em consonância com as diretrizes, metas e estratégias previstas neste PNE, no prazo de um ano contado da publicação desta lei (BRASIL, 2014).

O novo PEEMS, foi aprovado e lançado com 20 metas a serem alcançadas durante o decênio de 2014 a 2024. Tais metas dizem respeito à educação infantil, ensino fundamental, ensino médio, educação especial, alfabetização, educação em tempo integral, qualidade da educação, escolaridade média da população, alfabetização e analfabetismo, educação de jovens e adultos e educação profissional, educação profissional técnica de nível médio, educação superior, valorização do magistério, gestão democrática, e financiamento da educação. Cada um desses temas possui suas metas, análise situacional e estratégias especificadas no texto do plano.

O texto introdutório do documento ressalta o caráter de política de Estado do plano, reverencia a diversidade social e étnica do estado, e expõe como grandes desafios à sua educação escolar: assegurar o acesso, a permanência com qualidade social e o êxito no processo de escolarização. Afirma, ainda, a necessidade de se aprofundarem os debates no estado sobre qual educação pretende-se oferecer em MS, o que nos remete às discussões sobre a necessidade de esclarecimento sobre qual padrão de qualidade da educação deve ser colocado em prática em nosso país.

Nesse sentido, como objeto desse estudo foi eleita a meta 07 do PEEMS/2014, que tem como tema a qualidade na educação. A meta a ser alcançada no que tange a esse tema durante o decênio é: "fomentar a qualidade da educação básica em todas as etapas e modalidades, com melhoria do fluxo escolar e da aprendizagem de modo a atingir as médias nacionais para o ideb" (SED/MS, 2014, p. 49). Seguindo a ótica nacional, esse plano considera a melhoria no fluxo escolar e da aprendizagem como sinônimos de qualidade e utiliza o Ideb como seu aferidor.

Assim como as demais, a meta 07 possui uma análise situacional onde é descrito o cenário educacional do estado por meio de dados estatísticos, bem como o que se tem concebido por qualidade da educação. Seu texto está inspirado na atual percepção de 
educação impregnada nas políticas públicas nacionais, que se pautam em notas de provas em larga escala e, principalmente, na elevação do ideb como caminhos para se atingir qualidade, como pode ser observado adiante.

É fazendo menção ao art. 206 da Constituição Federal de 1988 que se inicia a análise em questão; tal artigo determina que um dos princípios básicos da educação brasileira seja a garantia do padrão de qualidade. Tem-se a ideia de que é necessário que exista o regime de colaboração entre a União, o Distrito Federal, os estados e os municípios para que a educação seja qualificada; ressalta-se ainda a função redistributiva e supletiva da União na garantia de um padrão mínimo de qualidade, conforme consta no art. 211 da Carta Magna. Porém, assim como na Constituição, no plano estadual não fica evidente o que vem a ser ou a conter esse padrão de qualidade.

A Lei de Diretrizes e Bases da Educação Nacional de 1996 é citada em seu art. $4^{\circ}$, onde está especificado que o padrão mínimo de qualidade está associado à "variedade e quantidades mínimas, por aluno, de insumos indispensáveis ao desenvolvimento do processo de ensino-aprendizagem" (BRASIL, 1996). Porém, esta também se torna uma especificação um tanto superficial diante da tamanha responsabilidade que vem a ter o assunto no cenário, não só estadual, mas nacional.

A falta de uma particularização Legal sobre o que venha a ser o referido padrão pode ser a justificativa para que o texto do PEEMS/2014 afirme que "definir qualidade não é algo simples [...] é um fenômeno complexo e abrangente, de múltiplas dimensões", e eleja a avaliação como aspecto fundamental para a promoção e garantia da educação de qualidade: "um aspecto fundamental para a promoção e garantia da educação de qualidade é a avaliação, não apenas da aprendizagem, mas também das variáveis que, dentre outras, a viabilizam" (SED/MS, 2014, p. 49).

Faz-se necessário salientar que as avaliações em larga escala têm como função aferir condições, e que por si só não garantem a promoção da qualidade da educação como se refere o plano; para que essa garantia seja viabilizada, mais que avaliar, é preciso esclarecer qual qualidade se almeja e, assim, pôr em prática ações de melhorias coerentes para alcançá-la.

Contextualizando o cenário educacional estadual em que o plano foi concebido, tem-se a exposição de alguns números que por si só falam muito, a começar pelas matrículas. Dados do censo escolar revelam um aumento de 362 matrículas de 2012 para 2013 no ensino médio da rede federal de ensino, porém, quando considerada as 
redes privadas, municipais e estaduais, visualiza-se uma diminuição de 1077 alunos (SED/MS, 2014).

No ensino fundamental, essa situação é um pouco mais preocupante, pois mesmo havendo um aumento de 553 matrículas na rede privada de ensino entre esses anos, ao reunir as demais redes vê-se uma baixa de 9.240 matriculas (SED/MS, 2014). É necessário destacar que tais baixas podem ser justificadas em parte pela queda na taxa de natalidade brasileira entre os anos 2000 e 2015 , que caiu de 20,86\% para $14,16 \%$, segundo dados da projeção da população do Brasil do IBGE (2013).

Com relação à análise do número de estabelecimentos de ensino no estado, destaca-se o crescimento de instituições estaduais ofertantes da educação profissional de 2012 para 2013, passando de 35 para 69 instituições; esta ampliação pode ser justificada pelo Programa Nacional de Acesso ao Ensino Técnico e Emprego (Pronatec); neste período houve uma acentuada oferta de vagas para cursos de qualificação profissional e técnicos por meio desse programa. Em contrapartida, uma escola estadual e três municipais deixaram de ofertar o ensino fundamental e três escolas estaduais deixaram de ofertar o ensino médio, o que pode ser reflexo da diminuição de matrículas exposta no parágrafo anterior (SED/MS, 2014).

A análise situacional da meta 7 do PEEMS/2014 também faz menção à infraestrutura das instituições de ensino públicas do estado com base no censo escolar 2011, nesta pode-se dar ênfase ao fato de que 99\% das escolas possuem laboratório de informática, $88 \%$ possuem água via rede pública, $100 \%$ com energia via rede pública, 92\% com coleta de lixo periódica e $98 \%$ dos professores atuantes na rede pública possuem ensino superior. Em contraponto, apenas 37\% dessas instituições possuem esgoto via rede pública, $55 \%$ dispõem de acessibilidade às pessoas com deficiência e $56 \%$ possuem bibliotecas. Verifica-se um aumento significativo na presença de equipamentos de multimídia (computadores, projetores, DVDs, entre outros) nas escolas, bem como no acesso à internet banda larga (SED/MS, 2014).

Com relação ao fluxo escolar, é dado destaque às altas taxas de abandono do aluno do ensino médio e ao significativo número de distorção idade/série do ensino fundamental público, com 28,7\%, e no ensino médio, também público, com $35 \%$, ambos no ano de 2013. Esse fato nos remete à aprendizagem do aluno; para situar esse quesito os dados apresentados no plano estadual são os resultados da Prova Brasil de 2011 e as notas do Ideb até 2013. Verifica-se que dos 35.612 alunos do $5^{\circ}$ ano do ensino fundamental que fizeram a prova, 15.497 demonstraram um aprendizado adequado em 
português e apenas 13.722 demonstraram aprendizado suficiente em matemática. Com relação ao $9^{\circ}$ ano, esses dados são mais preocupantes, dos 34.330 alunos participantes, 9.141 demonstraram o aprendizado adequado em português e somente 5.158 demonstraram o aprendizado adequado em matemática (SED/MS, 2014).

No que diz respeito ao Ideb do estado, verifica-se que nas séries iniciais do ensino fundamental houve a superação das metas projetadas até o índice lançado em 2013, sendo este utilizado para a escrita do plano; acrescenta-se que em 2015 também houve esta superação, o que não se pode dizer das séries finais e do ensino médio, uma vez que suas metas não vêm sendo atingidas desde o cálculo de 2013, tendo o ensino médio até retrocedido nas aferições de 2013 e 2015.

Nesse sentido, ao relacionar os dados estatísticos de abandono e distorção idade/série com as notas da Prova Brasil e o Ideb, constata-se que o acesso à escola e ao conhecimento vai se afunilando com o passar dos anos de estudos no MS, com maior gravidade para o ensino médio. No entanto, esta não é uma especificidade desse estado, sendo uma condição presente em grande parte do país. Uma amostra desta situação está no censo escolar de 2015 (MEC/INEP, 2016), quando no ano de 2014 houve 8.300.189 matrículas no ensino médio brasileiro, porém a contagem populacional na faixa etária de 15 a 17 anos era de 10.547.337, sem esquecer que há nesse meio as matrículas em situação de distorção idade/série.

A análise situacional da meta 07 é concluída com a ciência de que ainda há muito por se fazer pela qualidade da educação pública ofertada no estado, mas que não se pode considerar o Ideb como única referência de qualidade e que é necessário "pensar em uma política de avaliação sistêmica que seja entendida como um processo contínuo e que contribua para o desenvolvimento dos sistemas de ensino e do processo ensino e aprendizagem" (SED/MS, 2014, p. 55).

Com esta visão da avaliação como propulsora da qualidade da educação, em 2003 o MS criou seu próprio sistema de avaliação, denominado Sistema de Avaliação da Educação Básica do Estado de Mato Grosso do Sul (SAEMS). Seguindo a lógica nacional, o foco de aferição deste sistema são as disciplinas de Português e Matemática, porém sua aplicabilidade é variável, contemplando séries diferentes a cada ano no contexto do ensino fundamental, médio e educação de jovens e adultos.

Com base no contexto descrito acima, o Plano Estadual de Educação de MS projeta 50 estratégias visando o alcance de sua meta 07 . Como são inúmeras, não serão 
aqui discutidas na íntegra, mas sintetizadas por categorias para situar o leitor; segue no quadro abaixo:

Quadro 1: síntese das estratégias da meta 07 do PEEMS/2014

\section{Avaliação}

- promover auto avaliação das escolas no que tange ao planejamento estratégico, à melhoria contínua da qualidade educacional, à formação continuada dos profissionais da educação e ao aprimoramento da gestão democrática;

- acompanhar, orientar e avaliar as políticas das redes públicas de ensino no sentido de reduzir a diferença das notas do Ideb entre as escolas;

- aplicar os instrumentos de avaliação nacionais e estaduais, com divulgação de resultados;

- incorporar o ENEM às avaliações já existentes;

- proposição de avaliação da qualidade da educação especial;

- fortalecer, com a colaboração técnica e financeira da União, o sistema estadual de avaliação da educação básica, com participação das escolas públicas e privadas;

- criar o observatório do PEEMS no âmbito dos fóruns de educação para o monitoramento do cumprimento das metas deste e divulgação dos resultados;

\section{Infraestrutura}

- garantir até o quinto ano da vigência deste plano, estrutura adequada e promover a utilização de tecnologias educacionais, entre elas o acesso à rede mundial de computadores para toda a educação básica, bem como promover o aprimoramento destas tecnologias;

- aprimorar o atendimento ao estudante no que tange a: material didático-escolar; transporte público adequado, gratuito, acessível e seguro; alimentação; e assistência à saúde;

- garantir o acesso à rede elétrica, abastecimento de água, esgoto sanitário e ao manejo de resíduos sólidos;

- proporcionar a acessibilidade nas escolas;

- universalizar bibliotecas com acesso à internet banda larga até o quinto ano deste plano; e desenvolver formação de leitores e capacitação dos profissionais da educação para atuarem como mediadores da leitura;

- informatizar a gestão escolar das escolas públicas, objetivando a construção e implementação de sistemas integrados até o quinto ano de vigência;

- "implantar nas escolas da rede pública um programa que valorize o conforto, a segurança e o bem-estar nos espaços escolares, com arborização, iluminação, climatização, manutenção dos prédios e mobiliários suficientes e adequados" (p.59);

\section{Formação}

- formação para técnicos escolares;

- formar gestores, profissionais da educação e alunos sobre: "direitos humanos, promoção da saúde e prevenção das DST/Aids, alcoolismo e drogas, em sua interface com as questões de gênero e sexualidade, questões étnico-raciais, geracionais, situação das pessoas com deficiência" (p. 57);

- formação dos sujeitos escolares no que diz respeito à preservação da memória municipal, estadual e nacional; respeito e valorização aos idosos;

\section{Currículo, Cultura e Diversidade}

- estabelecer e implantar diretrizes pedagógicas para a educação básica e a base nacional comum dos currículos; 
- promover propostas alternativas de atendimento escolar à diversidade cultural e étnica do estado: quilombolas, indígenas, população do campo, fronteiriças e povos das águas;

- garantir, até dois anos após a vigência deste plano, acesso a todos os alunos a bens culturais e artísticos, brinquedotecas, bibliotecas, equipamentos e laboratórios de ensino; e integrar a escola a instituições e movimentos culturais;

- elaborar materiais didáticos sobre: "direitos humanos, promoção da saúde e prevenção das DST/Aids, alcoolismo e drogas, em sua interface com as questões de gênero e sexualidade, questões étnico-raciais, geracionais, situação das pessoas com deficiência" (p. 57);

\section{Aprendizagem}

- elevar o nível de aprendizado de pelo menos $70 \%$ alunos até o quinto ano da vigência do plano ao patamar de desejável e ao último ano levar $80 \%$ ao nível desejável. Bem como diminuir as taxas de abandono, evasão e distorção idade/série;

\section{Políticas}

- cumprir com as estratégias do Plano de Ações Articuladas;

- prestar assistência técnico financeira às redes públicas com Ideb abaixo da média nacional;

- participar em regime de colaboração com a União e os demais entes federados da definição dos parâmetros mínimos de qualidade dos serviços da educação básica;

- implantar e desenvolver políticas de combate e prevenção à violência na escola;

- elaboração de políticas para a inclusão de jovens em situação de liberdade assistida com vistas à permanência na escola;

\section{Sociedade}

- promover maior controle social nos planejamentos, políticas públicas educacionais e recursos financeiros, efetivar a gestão democrática;

- até o quinto ano de vigência deste plano deve ser consolidada a oferta com qualidade social da educação escolar à população do campo, povos das águas, comunidades fronteiriças, populações itinerantes e comunidades indígenas e quilombolas, respeitando a articulação entre os ambientes escolares e comunitários;

- promover a articulação da educação com outras áreas sociais, como saúde, trabalho e emprego, assistência social, esporte e cultura, possibilitando a criação de redes de apoio integral às famílias, em especial nas áreas de maior vulnerabilidade social;

- "propiciar e fomentar discussões e mobilizar a sociedade para a aprovação da Lei de responsabilidade Educacional (LRE), pelo Congresso Nacional” (p.59).

Fonte: Formulação própria a partir de dados coletados no PEEMS (SED/MS, 2014).

A partir das estratégias, visualiza-se que o plano reconhece o déficit estrutural das escolas públicas do estado, na medida em que direciona várias estratégias para essa categoria que atendem desde o fornecimento de energia elétrica e água até a modernização do sistema escolar e universalização do acesso à internet banda larga; há também uma valorização da grande diversidade social do MS quando busca adequação do currículo escolar para atender as especificidades de cada comunidade. Sobre a aprendizagem, não formula estratégias diretamente, há somente uma meta numérica a 
ser atingida nas avaliações em larga escala. Isso não quer dizer que as estratégias propostas nas demais categorias não podem gerar bons resultados para a aprendizagem do aluno, pois podem incidir indiretamente nesse processo.

No que tange à sociedade, o plano instiga a população a ter um maior controle social sobre o processo de aprendizagem e sobre os assuntos burocráticos da escola, que passam pela efetivação de uma gestão democrática até o controle das finanças. Também é feito o envolvimento da educação escolarizada com outros setores da sociedade, como saúde, trabalho, esporte, assistência social, entre outros; esta relação também fica visível nas categorias "política", "currículo, cultura e diversidade" e "formação".

Destaca-se a inserção da qualidade socialmente referenciada na estratégia de base para a escolarização das comunidades minoritárias do estado (população do campo, povos das águas, comunidades fronteiriças, populações itinerantes e comunidades indígenas e quilombolas); infelizmente, o conceito não foi aderido para a educação do restante da população nesta meta.

Porém, o que fica mais visível nas estratégias da meta 07 é a condição do estado como regulador e avaliador, e a ênfase atribuída às avaliações em larga escala, primeiro pelo fato do estado possuir seu próprio sistema de avaliação educacional, o SAEMS. Este, que segundo pesquisa desenvolvida por Sayão (2017), tem se configurado, em sua metodologia, como uma das principais estratégias das políticas educacionais neotecnicistas, na perspectiva de mecanismo de gestão e melhoria da qualidade da educação, via regulação gerencial.

Segundo, por dar grande espaço às avaliações estadual e nacional, ou melhor, aos resultados finais, tem desconsiderado a prática pedagógica e o processo de ensino e aprendizagem como um construto social, político e cultural; tanto que, em meio à meta sobre qualidade da educação, não há nenhuma estratégia que faça referência à prática cotidiana docente como ação reflexiva, aos planejamentos de aulas, à relação professor e aluno, entre outros fatores que podem qualificar a educação socialmente.

Nesse sentido, fica perceptível o viés neoliberal do PEEMS/2014 em considerar os resultados das avaliações como sinônimos de qualidade educacional, podendo se dizer que a qualidade da educação escolar resultaria de uma adequada revisão curricular, da eficiência da gestão institucional e da competitividade deflagrada por um processo de avaliação externa (FONSECA, 2009).

Krawczyk (2005) vem relacionar a utilização de avaliações em larga escala à cultura de descentralização presente nas reformas educacionais das últimas décadas e 
menciona que, sob o discurso da necessidade de realizar uma mudança sistêmica, o Estado tem promovido um conjunto de mudanças estruturais no âmbito educacional que muda não apenas a qualidade do direito à educação, mas rompe a lógica de suas demandas sociais.

Desta forma, pode-se afirmar que as diretrizes do PEEMS/2014 são coerentes com a qualidade socialmente referenciada tão almejada para a educação, porém, o seu desdobramento nas metas e estratégias da meta 07 deixa visível as características do viés mercadológico de qualidade, em que se aguça a competitividade, fragmenta-se o conhecimento, dá-se ênfase na auto avaliação e na formação do sujeito como trabalhador, prima-se pelos resultados e não pelo processo, enfim, há um alto poder de regulação e avaliação, mas com pouca intervenção financeira.

\section{Considerações finais}

O cenário educacional atual tem abarcado uma gama de fatores que podem ter aportes teóricos distintos, variando de acordo com o contexto em que estão inseridos e das influências exercidas; a qualidade e o planejamento são exemplos destes fatores. Ao longo dos anos, com discursos democratizantes de participação, o Ministério da Educação incorporou em suas políticas educacionais o conceito de qualidade social sugerido pelos educadores, porém, a este tem relacionado instrumentos de atuação que se remetem aos aportes gerencialistas. Tal relação tem reflexo direto nos demais entes federativos, como é o caso do estado de MS, foco deste estudo.

A literatura demonstra que o conceito de qualidade é bem complexo, e essa condição ainda piora quando não se sabe legalmente o que uma rede pública de ensino precisa ter para ser de qualidade, como é o caso da educação brasileira, onde as leis falam de um padrão, mas não deixam claro o que contempla esse padrão; dando, assim, abertura para várias interpretações por parte de estados e municípios. No caso de MS, a centralidade nas avaliações em larga escala se tornou sinônimo de qualidade.

No entanto, fica aqui uma incoerência do PEEMS/2014 em atribuir somente à avaliação a responsabilidade por qualificar a educação, uma vez que esta é capaz apenas de diagnosticar a situação. Os avanços são sentidos quando uma das estratégias da meta 07 propõe a participação do estado nas discussões e decisões sobre a definição dos parâmetros mínimos de qualidade dos serviços da educação básica juntamente com o 
Ministério da Educação. Mas por enquanto, o padrão de qualidade da educação ainda permanece sendo um grande fosso.

As estratégias propostas pela meta 07 são coerentes, porém há a necessidade de um desprendimento dos resultados das avaliações, pois estas não refletem o real aprendizado; é urgente que haja um voltar-se para o ensino e a aprendizagem, uma vez que este é um processo dinâmico e é momento de construção de conhecimento, por isso, deve se considerar os alunos em suas especificidades e os professores como protagonistas de sua prática, o que a mecanicidade de uma prova padronizada não permite avaliar.

\section{REFERÊNCIAS}

BRASIL. Congresso Nacional. Constituição da República Federativa do Brasil. Brasília: Senado Federal, Centro gráfico, 1988.

BRASIL. Lei n ${ }^{\circ}$ 9.394, de 20 de dezembro de 1996. Lei de Diretrizes e Bases da Educação Nacional (LDB). Brasília, DF: Senado Federal, 1996.

BRASIL. Lei $\mathbf{n}^{\circ} \mathbf{. 1 3 . 0 0 5}$, de 25 de junho de 2014. Aprova o Plano Nacional de Educação e dá outras providencias, publicada no DOU. Brasília, DF: Senado Federal, 2014.

DEMO, P. Educação e Qualidade. 10. ed. Campinas: Papirus, 2006.

DOURADO, L. F.; OLIVEIRA, J. F.; SANTOS, C. A. Qualidade da educação: conceitos e definições. Brasília: INEP, 2007. 65 p.

ENGUITA, M. F. O discurso da qualidade e a qualidade do discurso. In. GENTILI, P. A. A; SILVA, T. T. da. Neoliberalismo, Qualidade Total e Educação. Petrópolis/RJ: ed. Vozes, 1996.

FONSECA, M. Políticas públicas para a qualidade da educação brasileira: entre o utilitarismo econômico e a responsabilidade social. Cad. Cedes, Campinas, v. 29, n. 78, p. 153-177, maio/ago., 2009.

\section{FONSECA, Z. V. D.; OLIVEIRA, N. C. M. de. Qualidade da Educação Pública}

Brasileira: as diferentes perspectivas em disputa. Porto Alegre:

UFRGS/FACED/PPGEDU, 2007.

FREITAS, D. N. T. de. Ação reguladora da União e qualidade do ensino obrigatório (Brasil, 1988-2007). Revista Educar, n. 31, p. 33-51, 2008.

GENTILI, P. A. A. Adeus à escola pública: a desordem neoliberal, a violência do mercado e o destino da educação das maiorias. In: GENTILI, P. (org.). Pedagogia da exclusão. 13 ed. Petrópolis: Vozes, 2007. 
IBGE. Taxa bruta de natalidade. 2013. Disponível em:

<http://brasilemsintese.ibge.gov.br/populacao/taxas-brutas-de-natalidade.html >. Acesso em: 28 jun. 2017.

KRAWCZYK, N. R. Políticas de regulação e mercantilização da educação: socialização para uma nova cidadania? Educação \& Sociedade, Campinas, v. 26, n. 92, p. 799-819, Especial, out., 2005.

LIBÂNEO, J. C.; OLIVEIRA, J. F. de; TOSCHI, M. S. Educação escolar: políticas, estrutura e organização. São Paulo: Cortez, 2008.

MEC/INEP. Censo escolar 2015: notas estatísticas. Brasília-DF: MEC/INEP, 2016.

OLIVEIRA, R. P. Da universalização do ensino fundamental ao desafio da qualidade: uma análise histórica. Educação \& Sociedade, out. 2007, vol.28, no.100, p.661-690. ISSN 0101-7330.

OLIVEIRA, R. P.; ARAUJO, G. C. de. Qualidade do ensino: uma nova dimensão da luta pelo direito à educação. Revista Brasileira de Educação, Rio de Janeiro, n. 28, 2005. Disponível em: http://www.scielo.br/scielo. Acesso em: 11 Abr. 2007.

PARO. V. H. A gestão da educação ante as exigências de qualidade e produtividade da escola pública. In. SILVA, L. H. da; (org.) A escola cidadã no contexto da globalização. Petrópolis, Vozes, 1998. p. 300-307.

SAYÃO, L. G. dos S. Condicionantes da política: a formulação do Sistema de Avaliação da Educação da rede pública de Mato Grosso do Sul - SAEMS. Dissertação de Mestrado. Dourados, MS: UFGD, 2017.

SED/MS. Lei n ${ }^{\circ}$ 4.621 de 22 dez. 2014. Institui o Plano Estadual de Educação de Mato Grosso do Sul. Campo Grande: SED, 2014.

SILVA, M. A. da. Qualidade social da educação pública: algumas aproximações.

Caderno CEDES, v. 29, n. 78, p. 216-226, 2009. ISSN 0101-3262.

WARDE, M. J. As políticas das organizações internacionais para a educação. Em Aberto. Brasília, ano 11, n 5 6, out./dez., 1992.

\section{Como referenciar este artigo}

AMORIM, Milene Dias. Políticas de qualificação da educação: a meta 07 do Plano Estadual de Educação de MS em questão. Revista on line de Política e Gestão Educacional, Araraquara, v. 22, n. 2, p. 482-497, maio/ago., 2018. ISSN: 1519-9029. DOI: $10.22633 /$ rpge.v22.n2.maio/ago.2018.11168

Submetido em: 06/03/2018

Revisões Requeridas: 16/04/2018

Aprovado em: 19/06/2018 